\title{
Improved methods for generating and estimating turbulence in tanks suitable for fish larvae experiments*
}

\author{
JAN ERIK STIANSEN and SVEIN SUNDBY \\ Institute of Marine Research, P.O. Box 1870 Nordnes, 5817 Bergen, Norway. E-mail: jan.erik.stiansen@imr.no
}

\begin{abstract}
SUMMARY: An experimental design has been developed for the purpose of testing the response of larval fish feeding to turbulence. The main purpose of the design is to reproduce natural turbulence within the range of scales relevant to the feeding processes. The design is based on grid-generated turbulence in a circular tank with a diameter of $1.5 \mathrm{~m}$ and a water depth of $0.90 \mathrm{~m}$. The spatial distribution of the turbulence was measured. The data analysis of our experiment indicate that we successfully simulated natural turbulence covering six orders of magnitude for the energy dissipation rate $\left(4 * 10^{-11}-2 * 10^{-4}\right.$ $\mathrm{W} / \mathrm{kg})$ and over three orders of spatial scales from the Kolmogorov microscale $(0.3 \mathrm{~mm}-13 \mathrm{~mm})$ to the size of the tank. It is concluded that the tank is well designed for studies of zooplankton - larval fish interactions, as the turbulence is generated on a range of scales similar to the separation distance between the zooplankton particles found in nature. The short and relatively slow movement of the grid in addition to the relatively large volume of water should make it possible for the larvae to avoid extreme shears, and minimises mechanical impact on larvae behaviour compared to other known turbulence generating systems. A method is developed to calculate the turbulent energy dissipation rate in a zero mean velocity field, assuming the turbulent cascade follows a $-5 / 3$ law in the inertial subrange. This method is also expanded for use on noisy time series. Comparisons with five other methods have been conducted. The comparisons show that Taylors "frozen turbulence" hypothesis can be used even when the ratio between the turbulent and the mean velocity is approximately 1 .
\end{abstract}

Key words: energy dissipation rate, energy spectra, fish larvae, grid-generated turbulence, mesocosm, turbulence.

\section{INTRODUCTION}

In contrast to large marine organisms like nekton, which can fully control their position in the sea by swimming, the positioning of planktonic organisms, from ichtyoplankton to phytoplankton, are strongly influenced by the motion in the sea. Their ways to interact with motion in order to control their position is through their buoyancy, shape and their limited way of swimming. There is a multitude of ways in which motion can influence plankton dynamics.

\footnotetext{
*Received July 6, 2000. Accepted January 22, 2001.
}

Water motion will influence the spatial distribution of a plankton cohort, it will influence the relative motion between individual planktonic organisms (predator-prey interrelations) and it will influence the transport of dissolved substances to the surface of the plankton. From the late 1980s the number of studies dealing with the influence of turbulence have increased considerably (Peters and Redondo, 1997), particularly the effects of turbulence on predatorprey interrelations and plankton contact rates as a result of the work by Rothschild and Osborn (1988). It should be emphasised, however, that not only turbulence influences plankton contact rates but so 
does structured water motions like current shear and gyre. On the other hand, there is no doubt that turbulence is a major factor in planktonic predator-prey interactions. There are, however, many unexplored aspects of the general theory developed by Rothschild and Osborn (1988). This is because the large variety of plankton organisms have developed a multitude of adaptive behaviours to cope with turbulent motion depending on their size, shape, buoyancy, sensory development, motion, prey reaction and typical concentration (e.g. Kiørboe, 1993).

The theory of the effect of turbulence on plankton contact rates (Rothschild and Osborn, 1988) indicates that turbulence substantially influences feeding rates of predators. Fish larvae and early juveniles are among the largest planktonic organisms whose feeding is influenced by turbulence. Field evidence for the effect of turbulence on their feeding conditions is scarce, most probably because of the large multitude of adaptive behaviours mentioned above which makes it difficult to keep control of all the variables and because of the difficulty in measuring turbulence or deriving the turbulent dissipation energy from bulk measurements. However, it has been shown in field studies on cod larvae feeding on Calanus nauplii that wind-induced turbulence affects the gut fullness of the cod larvae according to the theory (Sundby and Fossum, 1990; Sundby et al. 1994). Also, Gallego et al. (1996) following a patch of herring larvae found increasing growth rates in the turbulent environment. Irigoien et al. (2000) found a negative relationship between wind speed and gut fluorescence of the copepod Calanus finmarchicus in the field, but not between wind speed and egg production. However, the understanding of how turbulence influences all aspects of behaviour, feeding, metabolism and growth are still insufficiently understood. For example, an increasing feeding rate induced by turbulence might also cause a behaviour with excessive energy consumption which might counteract the effect of increased feeding on growth. Such aspects of turbulence indicated a need for experiments under controlled laboratory conditions to measure the actual growth and survival of the larvae.

However, most experimental set-ups on turbulence in the laboratory are made study fluid dynamics. For such conditions the processes to be studied are easily scaled down. Therefore, they have normally been conducted in relatively small jars. The famous experiments on turbulence by Kraus and Turner (Kraus and Turner, 1967, Turner and Kraus,
1967) were made in a 30 litre tank. Biological experiments on plankton in general, on the other hand, can not be scaled down in the same way. Plankton in natural conditions are found at specific concentrations that cannot necessarily be represented in small volumes. Phytoplankton and microzooplankton are found at very high concentrations and the length scales of the individuals imply that their motion are mainly controlled by the viscosity of the water. These kinds of organisms can be studied in quite small enclosures without making serious errors with respect to the physical dynamics. The fish larvae, on the other hand, have individual length scales of $\mathrm{mm}$ to $\mathrm{cm}$, and their motion is, to a much larger degree, dominated by inertial forces rather than viscous forces. The concentration in nature is considerably lower with characteristic peak concentrations of 1 individual per $\mathrm{m}^{3}$ or less which implies that the larvae are separated by the order of magnitude $1 \mathrm{~m}$ (Sundby, 1997). Their main prey, copepods nauplii, are found at typical concentrations 1000 times higher, i.e. several individuals per litre, which implies that the nauplii are separated by about 1-10 $\mathrm{cm}$. The study of planktonic behaviour and plankton interactions in small aquaria where concentrations have to be increased by several orders of magnitude compared to natural conditions could result in a multitude of artefacts of biological nature like density dependent stress, cannibalism and wall effects. Also, from a physical point of view, it is not possible in a small aquarium to reproduce natural motion linked to plankton dynamics in the field. Particularly, natural turbulence cannot be reproduced in a small aquarium as the upper range of turbulent length scales are necessarily limited to the spatial scale of the aquarium. Osborn and Scotti (1996) pointed out that in laboratory tanks of limited size the range between the energy containing eddies and the dissipation scale is not large enough to achieve the $\mathrm{k}^{-5 / 3}$ spectral relation found in natural systems. Lastly, as pointed out by Peters and Redondo (1997), in many laboratory plankton experiments the generated turbulent energy have been far too high compared to natural levels.

Turbulence should be generated on spatial scales relevant for fish larval foraging (Sundby, 1996). This means that length scales of turbulence from decimetres down towards the Kolmogorov scale of less than $1 \mathrm{~cm}$ should be reproduced according to the $-5 / 3$ wave number relation found in nature (Kolmogorov, 1941). Secondly, the mechanical device which generates the turbulence should not signifi- 
cantly influence larval feeding behaviour or the behaviour of the prey. Consequently, the experiment has to be made in a much larger tank than used by earlier investigators.

The general objective of the present work was to develop an experimental mesocosm set-up for more realistic study of macro zooplankton dynamics, particularly fish larval feeding, under various levels of controlled turbulent conditions. The first task was to measure the spatial structure of the turbulence in a mesocosm. The second task was to develop a method for calculating energy dissipation rates $(\varepsilon)$ from frequency spectra for laboratory conditions where the mean current velocity normally is small compared to the turbulent velocity. The third task was to compare the generated turbulence in the mesocosm with turbulence in nature.

\section{MATERIAL AND METHODS}

\section{Design of the tank and the oscillating grid}

The experiment was carried out in a circular laboratory tank at the Austevoll Aquaculture Station. The tank had a diameter of $1.5 \mathrm{~m}$ with a minimum depth of $1 \mathrm{~m}$ at the periphery, sloping slightly towards the centre (Fig. 1). The tank was filled to 10 $\mathrm{cm}$ from the top, giving a volume of approximately $1.6 \mathrm{~m}^{3}$. A horizontal grid was placed near the bottom of the tank. The grid was oscillating vertically by means of an arm hinged at the periphery of a rotating disc driven by an electrical engine. The lowest grid position was $5 \mathrm{~cm}$ above the bottom of the tank at the outer edge of the grid, and equal for all measurements. The stroke of the up-and-down moving grid was controlled by the radius of the disc and could be set to $4.5,9.1$ and $17.1 \mathrm{~cm}$. The frequency of the grid was adjustable from $1 / 30-1 \mathrm{~Hz}$ through frequency modulation of the electrical engine. For experiments, five fixed periods of oscillating grid were used: $1.5,5,9,13$ and 30 seconds. The fixed periods were kept approximately constant within a range of $+/-8 \%$. The diameter of the grid was $110 \mathrm{~cm}$ giving a gap of $20 \mathrm{~cm}$ between the edge of the grid and the tank wall.

Two different grids with bar width of $3 \mathrm{~cm}$ and $5 \mathrm{~cm}$ were tested. For both grids the mesh size was $10 \mathrm{~cm}$ and the bar thickness (vertical) was $1 \mathrm{~cm}$. The perpendicular bars were crossing on top of each other, resulting in an effective grid thickness of $2 \mathrm{~cm}$.

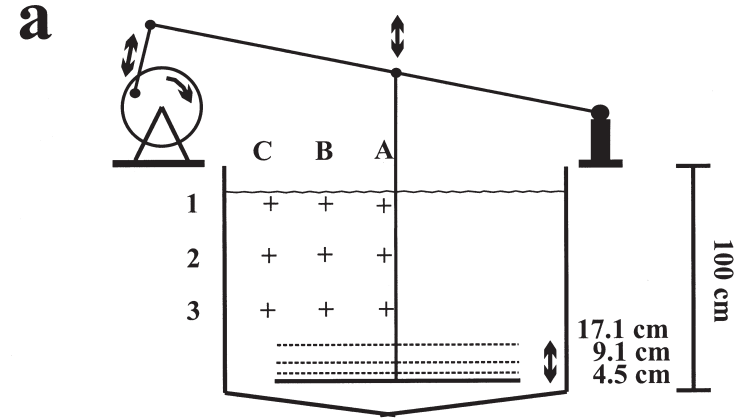

b

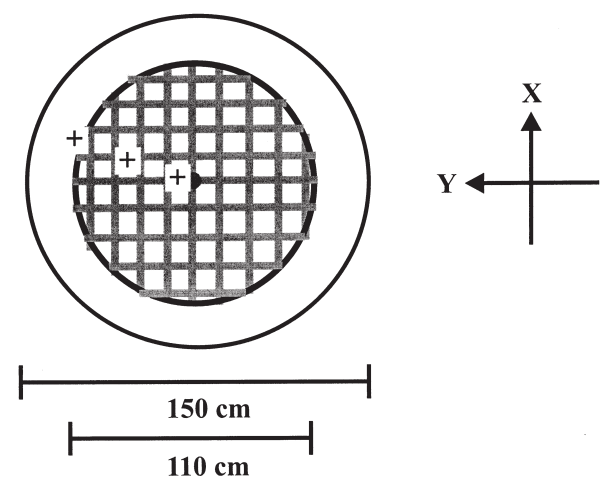

FIG. 1. - Sketch of the tank and turbulence generating system. a) The tank seen from the side. + marks the measuring positions, called $1 \mathrm{~A}, \ldots, 3 \mathrm{C}$, corresponding to the horizontal $(\mathrm{A}, \mathrm{B}$ and $\mathrm{C}$ ) and vertical $(1,2$ and 3$)$ indices. The thick line near the bottom of the tank gives the lowest position of the grid. This position was equal for all measurements. The dotted lines gives the highest position of the grid for the three different stokes $(4.5,9.1$ and $17.1 \mathrm{~cm})$. b) The tank seen from above. + marks the measuring positions. The coordinate system refers to velocity components ( $\mathrm{u}$ in the $\mathrm{x}$ direction and $\mathrm{v}$ in the $\mathrm{y}$ direction, $\mathrm{w}$ is the vertical direction, positively upwards)

\section{Current measurements and spectral analysis}

Nine measuring positions were occupied in the tank forming a measurement matrix of 3 depth levels and 3 horizontal positions. The depths levels were $30.5,52.5$ and $78 \mathrm{~cm}$ above the grid in its lower position. The horizontal positions were 17, 44.5 and $72 \mathrm{~cm}$ from the wall with the upper depth level 6.5 below the surface and the inner horizontal position $3 \mathrm{~cm}$ from the centre of the tank (indicated by the crosses in Fig. 1). For a specific chosen set of variables, a set of velocity time series was taken from some or all of the 9 positions. A total of 105 measurements were taken, distributed on 22 sets (of which 5 were taken in all 9 positions). The velocities were measured by an UCM-40 (Ultrasonic Current Meter) from Sensortec (see Gytre (1976) for description of the measurement principle). The instrument is a travel-time-difference current meter with a measuring frequency of $20 \mathrm{~Hz}$ and a velocity resolution of $1 \mathrm{~mm} / \mathrm{s}$. A data logging frequency of 2 
$\mathrm{Hz}$ (10 points average ) was used. Each series had a duration of at least $10 \mathrm{~min}$. The onset of the measurements were not started until the turbulent motion had reached a steady state, with at least 15 min between series and at least one hour between different settings.

The velocity data were divided into the three Cartesian velocity components, $\mathrm{u}$ (x-axis), $\mathrm{v}$ (y-axis) according to Figure $1 \mathrm{~b}$ and $\mathrm{w}$ (vertical). Because of magnetism in the laboratory we could unfortunately not rely on the internal compass of the UCM to derive the radial and transverse horizontal components and have therefore used the velocity components relative to the fixed instrument. For the same reason we have focused mostly on the vertical component, and treated this as a transverse velocity.

Energy density spectra (one-sided) were derived from $10 \mathrm{~min}$ long velocity series using the Fast Fourier Transform (FFT) from the statistical program SPLUS. A running average of 7 points were used on the spectral estimates.

\section{Calculation of the energy dissipation rate $(\varepsilon)$}

For small-scale homogenous, isotropic turbulence, Tennekes (1975) showed that turbulent energy in the inertial subrange of the frequency spectrum can be described by

$$
S(\omega)=B \varepsilon^{2 / 3} u_{r m s}^{2 / 3} \omega^{-5 / 3}
$$

where $S(\omega)$ is the spectral density at angular frequency $\omega . \mathrm{B}$ is a non-dimensional universal undetermined constant assumed to be of order one (Tennekes and Lumley, 1974). $\varepsilon$ is the energy dissipation rate and $u_{r m s}=\sqrt{\left(u^{\prime}\right)^{2}}$ is the-root-mean square of the turbulent velocity $\left(u^{\prime}\right)$. Lacking of a better value we used $\mathrm{B}=1.0$ in our calculations (see paragraph on Estimation of the energy dissipation rate in the Discussion).

Expressed in terms of the natural frequency, $f=\omega / 2 \pi$,

$$
S(f)=C_{f} \varepsilon^{2 / 3} u_{r m s}^{2 / 3} f^{-5 / 3}
$$

where $C_{f}=B(2 \pi)^{-2 / 3}$.

An expression for $\mathrm{S}$ as a function of the wave number, $\mathrm{k}$, can be derived from Kolmogorov's cascade theory and 2/3 law (Kolmogorov, 1941), which gives the equivalent wave numbers spectrum:

$$
S^{\prime}(k)=A \varepsilon^{2 / 3} k^{-5 / 3}
$$

where $S^{\prime}(k)$ is the spectral density at wavenumber $k$ and $\mathrm{A}$ is a universal constant of 1.5 in the threedimensional case (Tennekes and Lumley, 1974) and 0.5 in the one-dimensional case (Gross et al., 1994, Sreenivasan, 1995). This $\mathrm{k}^{-5 / 3}$ law is a result of Kolmogorov's 2/3 law and was first derived by Obukhov (1941a, b).

If the turbulent field can be assumed stationary, as well as homogenous and isotropic, the turbulent energy (E) of a water element can be measured in space (wavenumber) according to Equation 3 and in time (frequency) according to Equations 1 and 2. The relationship of the time and space domain is then given by equality between the respective integrated energy density spectra

$$
\left(E / 2=\int S(f) d f=\int S(\omega) d \omega=\int S^{\prime}(k) d k\right) .
$$

In a log-log plot of $S$ vs $\omega$ a straight line $(y=a x+b)$ can be fitted in the inertial subrange with $y=\log _{10}(S(\omega))$ and $x=\log _{10}(\omega)$. This gives

$$
\mathrm{S}(\omega)=\omega^{\mathrm{a}} \cdot 10^{\mathrm{b}}
$$

Assuming $\mathrm{a}=-5 / 3$, the slope of isotropic turbulence, comparison with Equation 1 gives $10^{\mathrm{b}}=\mathrm{B} \varepsilon^{2 / 3} u_{r m s}{ }^{2 / 3}$ and hence for angular frequency:

$$
\varepsilon=\left(\frac{10^{\mathrm{b}}}{B u_{r m s}^{2 / 3}}\right)^{3 / 2}
$$

For natural frequency, comparison of Equation 4 with Equation 2 gives:

$$
\varepsilon=2 \pi\left(\frac{10^{\mathrm{b}}}{B u_{r m s}^{2 / 3}}\right)^{3 / 2}
$$

The intersection coefficient $b$, in Equations 5 and 6 , is found from a linear regression of the log-log energy density spectrum of the measured time series using a fixed slope of $a=-5 / 3$. An advantage of using logarithms is that estimates are robust. We will in the following use the expressions for $\varepsilon$ in the natural frequency form (Eq. 6).

\section{Correction for noise measurements}

Traditionally a one-dimensional velocity field (u) is decomposed into an average (U) and a fluctuating (turbulent) part ( $\left.\mathrm{u}^{\prime}\right)$, the so-called Reynolds decomposition.

$$
\mathrm{u}=\mathrm{U}+\mathrm{u}^{\prime}
$$




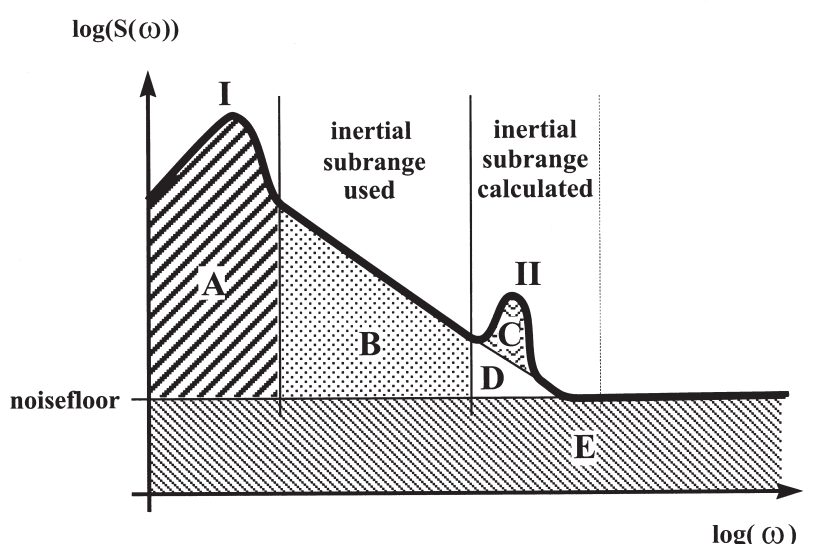

FIG. 2. - A conceptual figure of a typical energy density spectrum The turbulent energy source is on frequencies marked by (I) with another 'artificial' energy peak marked by (II), which do not contribute to turbulent energy. Area A is the contribution to the variance of the mean component (U). Area B and D are the undisturbed and the hidden part of the inertial subrange respectively, and are contributions to the variance by the turbulence $\left(\mathrm{u}_{\mathrm{rms}}\right)$. An artificial 'energy' source (for instance created by periodic movement of the current meter itself, or unwanted turbulence created by the instrument and advected into the measuring volume) on frequencies marked by (II) is shown in area C. This variance is from the same artificial, periodic movement, and does not contribute to the turbulent kinetic energy. Area E represents the uncorrelated white noise. Areas $\mathrm{C}$ and $\mathrm{E}$ are the contribution to the variance by the noise term $\left(u_{\text {noise }}\right)$. The vertical solid lines marks the inertial subrange used for calculations of the linear regression and the dotted line indicates the end of the inertial subrange towards higher frequencies.

where the average component represents the longterm structured variations (long compared to the turbulent field), such as a mean velocity field or a tidal current or wave motion (if we consider a time interval which is small compared to the periodic cycle).

If, in addition, a time series has a high noise level this has to be accounted for in order to find the true mean turbulent velocity $\left(\mathrm{u}_{\mathrm{rms}}\right)$. In studies on the influence of turbulence on plankton contact rates the small-scale turbulence is of particular interest. The measured velocity always contains noise, white noise (area E, Fig. 2) and noise on specific frequencies (area C, Fig. 2). The white noise is more important on high frequencies, where $S(\omega)$ is smaller, while both kinds of noise contributes to increase the $\mathrm{u}_{\mathrm{rms}}$ in general.

One way to handle this problem is to add a noise term to the decomposed velocity in Equation 7

$$
\mathrm{u}=\mathrm{U}+\mathrm{u}^{\prime}+\mathrm{u}_{\text {noise }}
$$

The equation is squared and time averaged:

$$
\begin{gathered}
\overline{u^{2}}=\left(\overline{U+u^{\prime}+u_{\text {noise }}}\right)^{2}= \\
=\overline{U^{2}}+\overline{u^{\prime 2}}+\overline{u_{\text {noise }}^{2}}+\overline{2 U u^{\prime}}+\overline{2 U u_{\text {noise }}}+\overline{2 u^{\prime} u_{\text {noise }}} .
\end{gathered}
$$

Rearranging the terms, assuming the noise and the fluctuating velocity component is uncorrelated and noting that $u_{r m s}=\sqrt{\overline{\left(u^{\prime}\right)^{2}}}$ and $\overline{U^{2}}=U^{2}$ Equation 9 reduces to

$$
u_{r m s}^{2}=\overline{u^{2}}-U^{2}-\overline{u_{\text {noise }}^{2}}
$$

The total 3D turbulent kinetic energy $\left(E_{k i n}\right)$ is given by $E_{k i n}=1 /{ }_{2} \bar{u}_{i}^{\prime} u_{j}^{\prime}$ where $\mathrm{i}=1,2,3$ and $\mathrm{j}=1,2,3$ denotes the components of the turbulent velocity. For isotropic conditions (no difference due to direction) terms of $i \neq j$ are zero and terms of $i=j$ are equal. This allows us to use the one-dimensional component ( $\left.u^{\prime}\right)$ to express the mean turbulent velocity, $\overline{u^{\prime}}=1 /{ }_{3} u_{i}^{\prime} u_{j}^{\prime}$ and arrive at the total $3 \mathrm{D}$ turbulent kinetic energy:

$$
E_{\text {kin }}=3 / 2 \overline{u^{\prime 2}}=3 / 2 u_{r m s}^{2}=3 / 2\left(\overline{u^{2}}-\overline{U^{2}}-\overline{u_{\text {noise }}^{2}}\right) .
$$

The calculation of the corrected $\mathrm{u}_{\mathrm{rms}}$ is easiest done in the Fourier transformed energy density spectrum, because the variance $u^{2}=2 \sum_{i=1}^{n} S\left(\omega_{i}\right) \Delta \omega$, where $\Delta \omega$ is the interval between the Fourier frequencies $\omega_{i}$ and $\omega_{i+1}$, and $n$ the number of Fourier frequencies. Figure 2 shows how the energy density spectrum can be divided into variances belonging to the different terms of Equation 10. Here the total variance $\left(\overline{u^{2}}\right)$ is the total area under the curve. The 'average' term $\left(\mathrm{U}^{2}\right)$ is represented in area $\mathrm{A}$, and represents both mean and larger periodic movements. The true turbulent variance is the sum of area $\mathrm{B}$ and $\mathrm{D}$. The noise term $\left(\overline{u_{\text {noise }}^{2}}\right)$ contains two parts. The first part is white noise, and is identical to the noise-floor (area E) because it is equal in all frequencies, due to factors such as the resolution of the current meter and electronic disturbances within the instrument. The second part is artificial or unwanted energy sources (area C). Artificial energy sources are peaks which do not contribute with turbulent energy, and are recognised by the fact that they do not raise the energy level $(-5 / 3$ line) on higher frequencies compared to frequencies lower than this peak. An example is an instrument which is not in complete steadiness but has some kind of small periodic movements. Since such movements are of the instrument and not of the water, they should be considered as false velocities. Vortices generated by the instrument and advected into the sampling volume is an example of an unwanted effect which increase 
the turbulence level locally, but actually is a bias when one looks at the system as a whole.

In the present tank experiment there were no significant peaks in the spectra on higher frequencies, or any long-term average velocities other than the sample mean. The energy dissipation rate was therefore calculated using the above method and correcting the $u_{r m s}$ only for the influence of the noise-floor. Regression lines were subjectively chosen for each series to give the best possible fit. Area D in Figure 2 was found by extrapolating the regression line to the Nyquist frequency.

Contour plots were made by interpolating the calculated energy dissipation rates from the 9 measurement locations onto an equally spaced grid with a resolution of $0.5 \mathrm{~cm}$.

Fish larvae often congregate in certain parts of an experimental aquarium. It is unclear why this happens, but it could be a result of one or several of the following factors: food aggregation, light conditions, the feeling of shelter and current structure. We therefore wanted to monitor structure of the current in the tank. Movement of soaked saw dust and milk were videotaped in the tank during some of the experiments in order to observe the spatial structure of the turbulence and to reveal if there were any structural circulation generated by the oscillating grid.

Pos: $1 \mathrm{C}$

Stroke: $17.1 \mathrm{~cm}$

Period: $5 \mathrm{~s}$

Bar: $5 \mathrm{~cm}$

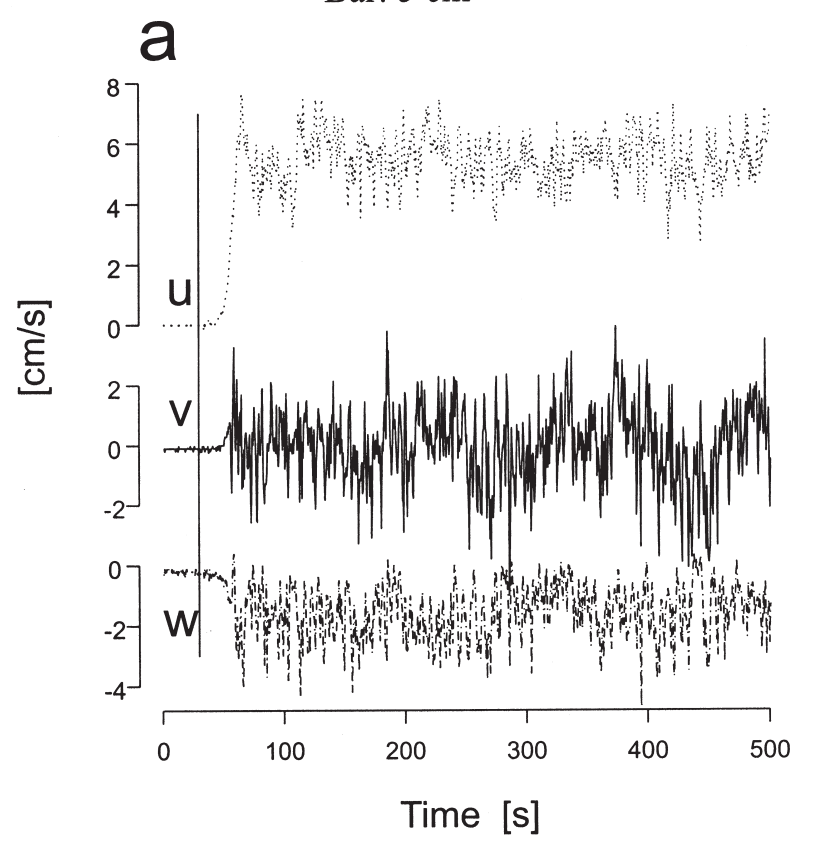

\section{RESULTS}

An experiment was made to measure the time it takes to generate fully developed turbulence from starting the oscillating grid (see Fig. 3a). The measurement was made at position $1 \mathrm{C}$, which is the maximum distance from centre of the grid, and thereby representative for the last area of the tank to be affected. About $30 \mathrm{~s}$ after start a local maximum occurred in all three velocity components, but the system did not seem to reach a stationary state until about $90 \mathrm{~s}$.

Another experiment was made on the decay time of the turbulence (see Fig. 3b) at position 3A, which is closest to the centre of the grid, and thereby in the area containing the highest energy level of the tank. After the oscillating grid was stopped the energy level dropped suddenly after about $25 \mathrm{~s}$, and vanished after about $200 \mathrm{~s}$.

The energy density spectra show good agreement with the theoretical slope of isotropic turbulence from Equation 2 (e.g. Figs. 4a and 4b). Due to the spatial resolution of the current meter the relationship is not so apparent in spectra with low turbulent levels (e.g. Fig. 4c). The estimated energy dissipation rates ranged from $4 * 10^{-11}$ to $2 * 10^{-4} \mathrm{~W} / \mathrm{kg}$, hence giving a six orders of magnitude range of

Pos: 3A

Stroke: $4.5 \mathrm{~cm}$

Period: $1.5 \mathrm{~s}$

Bar: $3 \mathrm{~cm}$
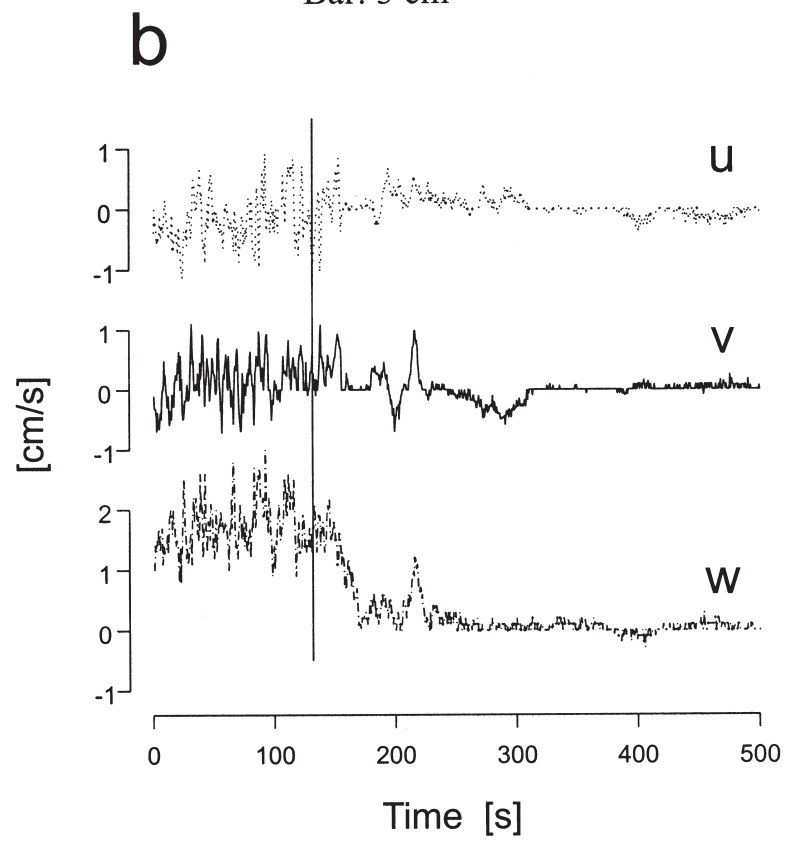

FIG. 3. - a) A spin-up time series for the three velocity components. The vertical line indicates when the grid movement was initiated. b) A decay time series for the three velocity components. The vertical line indicates when the grid movement was terminated. 

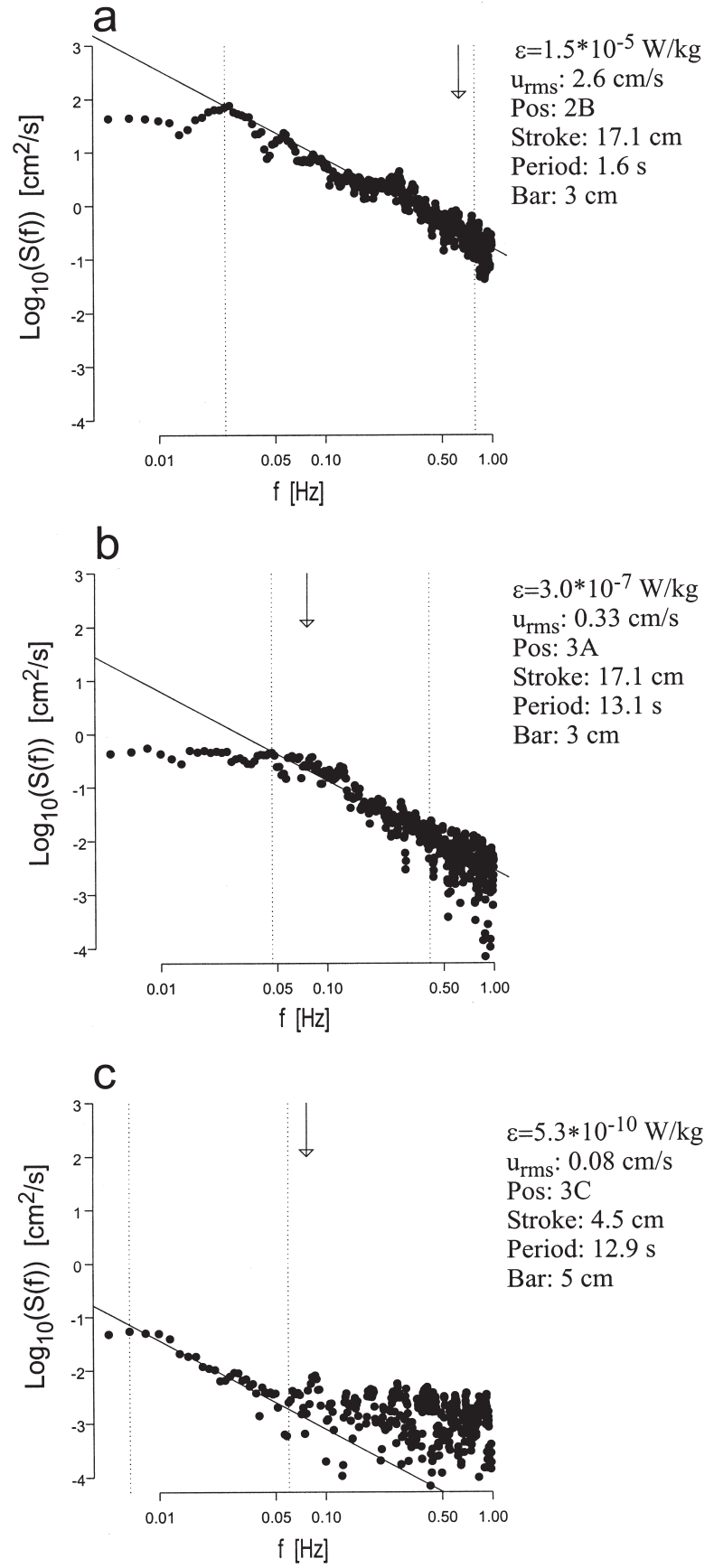

FIG. 4. - Log-log energy density spectra of the vertical component (w) for three different situations. The figures show how the energy was distributed at the range of frequencies. The frequency of the oscillating grid is indicated by the arrow in each case. A seven-point running average was used on the spectral estimates. The solid line is the regression line through the inertial subrange with a slope of $\mathrm{f}^{-5 / 3}$. The two vertical dotted lines mark both ends of the inertial subrange used in the calculation of the regression line. The horizontal dotted line marks the noise-floor level used in the calculations. a) A situation with high dissipation rate. The grid oscillation frequency was $0.63 \mathrm{~Hz}$ and $\mathrm{R}^{2}$ for the regression line is 0.89 . The noise-floor is $0.028 \mathrm{~cm}^{2} \mathrm{~s}^{-1}$ for each frequency. b) A situation with medium dissipation rate. The grid oscillation frequency was $0.08 \mathrm{~Hz}, \mathrm{R}^{2}$ is 0.85 and the noise-floor $0.0049 \mathrm{~cm}^{2} \mathrm{~s}^{-1}$ for each frequency. c) A situation with low dissipation. The grid oscillation frequency was $0.08 \mathrm{~Hz}, \mathrm{R}^{2}$ is 0.86 and the noise-floor $0.0036 \mathrm{~cm}^{2} \mathrm{~s}^{-1}$ for each frequency. Note the inverse cascade, which reaches much lower frequencies than the oscillation frequency in a) and c). variation. In Figures $4 \mathrm{a}$ and $4 \mathrm{~b}$ the maximal stroke of $17.1 \mathrm{~cm}$ was used and the bar width of the grid was $3 \mathrm{~cm}$. Figure $4 \mathrm{~b}$ represents an event of medium high energy level with a frequency of the moving grid of $13.1 \mathrm{~s}$, while Figure 4a represents an event of high turbulent energy level with a period of $1.6 \mathrm{sec}$. Estimates of energy dissipation rate were $3.0^{*} 10^{-7}$ and $1.5^{*} 10^{-5} \mathrm{~W} / \mathrm{kg}$, respectively. Figure $4 \mathrm{c}$ represents an event of low energy level where the minimum stroke of $4.5 \mathrm{~cm}$ was used together with a bar width of $5 \mathrm{~cm}$ and a period of $12.9 \mathrm{~s}$. The dissipation rate was $5.3^{*} 10^{-10} \mathrm{~W} / \mathrm{kg}$.

In all three figures the oscillation frequency is indicated by an arrow. The inertial subrange extended to much lower frequencies than the oscillation frequency in Figures $4 \mathrm{a}$ and $4 \mathrm{c}$. This inverse cascade (with turbulent energy propagating towards lower frequencies) was evident in most of the spectra, especially in situations of high and low turbulent levels.

The spatial contour plots of the distribution of turbulent kinetic energy in the tank showed a decrease with increasing distance from the grid. Figure 5 shows energy dissipation rates for the vertical velocity component, for different lengths of grid strokes, bar sizes and periods (inverse of frequency). Only small spatial differences were measured in the energy levels for medium and high turbulent events between the vertical and horizontal components (Figs. 5a-d). A dome shape distribution was present in the tank for all events with a maximum at the centre and the base of the tank and decreasing towards the surface and the periphery. (Note that Fig. 5 only shows the left half of the tank from the centre to the periphery.) For the weakest turbulent event (Fig. 5e) the decrease in turbulent energy was 5-10 times stronger in the vertical compared to the horizontal direction. There was a minimum in turbulent energy dissipation rate at middle depth and at one half radius $(1 / 2 * \mathrm{R})$ distance from the wall of the tank, while the turbulence maximum, seemed to occur at central middle depths.

The interval in energy dissipation rate spanned by all measuring series covered over six orders of magnitude, from $4 * 10^{-11}$ to $2 * 10^{-4} \mathrm{~W} / \mathrm{kg}$. Within the tank the energy level varied spatially by about one order of magnitude, with the strongest gradient close to the grid (Fig. 5). Thus, except close to the grid, most of the volume of the tank was approximately homogenous, with a spatial variation of less than one order of magnitude.

A decrease in bar size from 5 to $3 \mathrm{~cm}$ reduced the energy level almost one order of magnitude through- 

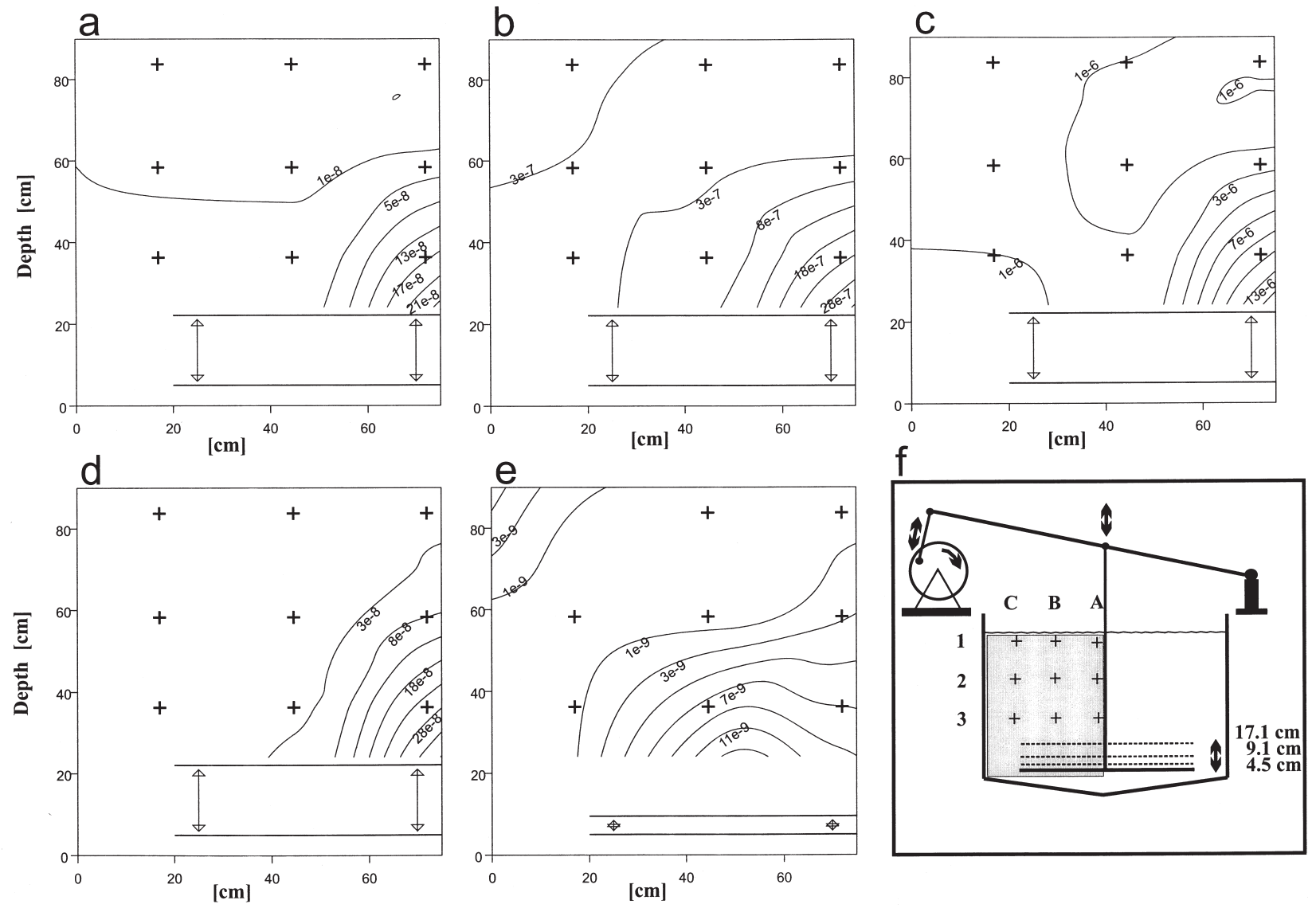

FIG. 5. - Contour plots of the energy dissipation rate vs. depth of the current meter for the vertical velocity component (w). a) Period $30 \mathrm{~s}$, stroke $17.1 \mathrm{~cm}$ and bar size $5 \mathrm{~cm}$. b) Period $13 \mathrm{~s}$, stroke $17.1 \mathrm{~cm}$ and bar size $5 \mathrm{~cm}$. c) Period $8.5 \mathrm{~s}$, stroke $17.1 \mathrm{~cm}$ and bar size $5 \mathrm{~cm}$. d) Period $13 \mathrm{~s}$, stroke $17.1 \mathrm{~cm}$ and bar size $3 \mathrm{~cm}$. e) Period $13 \mathrm{~s}$, stroke $4.5 \mathrm{~cm}$ and bar size $5 \mathrm{~cm}$. f) The tank with the measuring positions (marked with X's). The grey shaded area indicates the areas in which the contour plots have been estimated. Within a contour plot the isolines are equidistant and selected isolines are labelled with the dissipation value $(\mathrm{W} / \mathrm{kg})$.

TABLE 1. - Energy dissipation rates for grid size 3 and $5 \mathrm{~cm}$ in position 1C, 2B and 3A. Empty cells were not measured.

\begin{tabular}{|c|c|c|c|c|c|c|}
\hline Position / mesh size & Stroke $(\mathrm{cm})$ & 30 & 13 & $\begin{array}{c}\text { Period (s) } \\
9\end{array}$ & 5 & 1.5 \\
\hline $1 C / 3 \mathrm{~cm}$ & $\begin{array}{r}4.5 \\
9.1 \\
17.1\end{array}$ & $5.4 \mathrm{E}-10$ & $\begin{array}{l}4.1 \mathrm{E}-11 \\
4.6 \mathrm{E}-11 \\
2.1 \mathrm{E}-08\end{array}$ & & $\begin{array}{l}1.3 \mathrm{E}-09 \\
9.2 \mathrm{E}-07\end{array}$ & $\begin{array}{l}1.1 \mathrm{E}-07 \\
3.0 \mathrm{E}-05\end{array}$ \\
\hline $2 \mathrm{~B} / 3 \mathrm{~cm}$ & $\begin{array}{r}4.5 \\
9.1 \\
17.1\end{array}$ & $5.9 \mathrm{E}-10$ & $\begin{array}{l}9.0 \mathrm{E}-10 \\
6.1 \mathrm{E}-09\end{array}$ & & $\begin{array}{l}2.1 \mathrm{E}-09 \\
2.7 \mathrm{E}-07\end{array}$ & $\begin{array}{l}3.8 \mathrm{E}-08 \\
1.5 \mathrm{E}-05\end{array}$ \\
\hline $3 \mathrm{~A} / 3 \mathrm{~cm}$ & $\begin{array}{r}4.5 \\
9.1 \\
17.1\end{array}$ & $1.6 \mathrm{E}-08$ & $\begin{array}{l}3.4 \mathrm{E}-08 \\
3.0 \mathrm{E}-07\end{array}$ & & $\begin{array}{l}1.1 \mathrm{E}-08 \\
5.2 \mathrm{E}-06\end{array}$ & $\begin{array}{l}4.2 \mathrm{E}-07 \\
2.1 \mathrm{E}-04\end{array}$ \\
\hline $1 C / 5 \mathrm{~cm}$ & $\begin{array}{r}4.5 \\
9.1 \\
17.1\end{array}$ & 6.6E-09 & $\begin{array}{l}2.1 \mathrm{E}-08 \\
3.5 \mathrm{E}-07\end{array}$ & $1.3 \mathrm{E}-06$ & 7.5E-06 & \\
\hline $2 B / 5 \mathrm{~cm}$ & $\begin{array}{r}4.5 \\
9.1 \\
17.1\end{array}$ & $\begin{array}{l}4.6 \mathrm{E}-10 \\
2.8 \mathrm{E}-09\end{array}$ & $\begin{array}{l}5.6 \mathrm{E}-09 \\
2.2 \mathrm{E}-07\end{array}$ & 4.9E-07 & $\begin{array}{l}2.9 \mathrm{E}-07 \\
3.6 \mathrm{E}-06\end{array}$ & \\
\hline $3 \mathrm{~A} / 5 \mathrm{~cm}$ & $\begin{array}{r}4.5 \\
9.1 \\
17.1\end{array}$ & $\begin{array}{l}6.7 \mathrm{E}-09 \\
1.7 \mathrm{E}-07\end{array}$ & $\begin{array}{l}7.1 \mathrm{E}-09 \\
2.6 \mathrm{E}-07 \\
2.2 \mathrm{E}-06\end{array}$ & $1.1 \mathrm{E}-05$ & $\begin{array}{l}3.0 \mathrm{E}-06 \\
3.7 \mathrm{E}-05\end{array}$ & \\
\hline
\end{tabular}



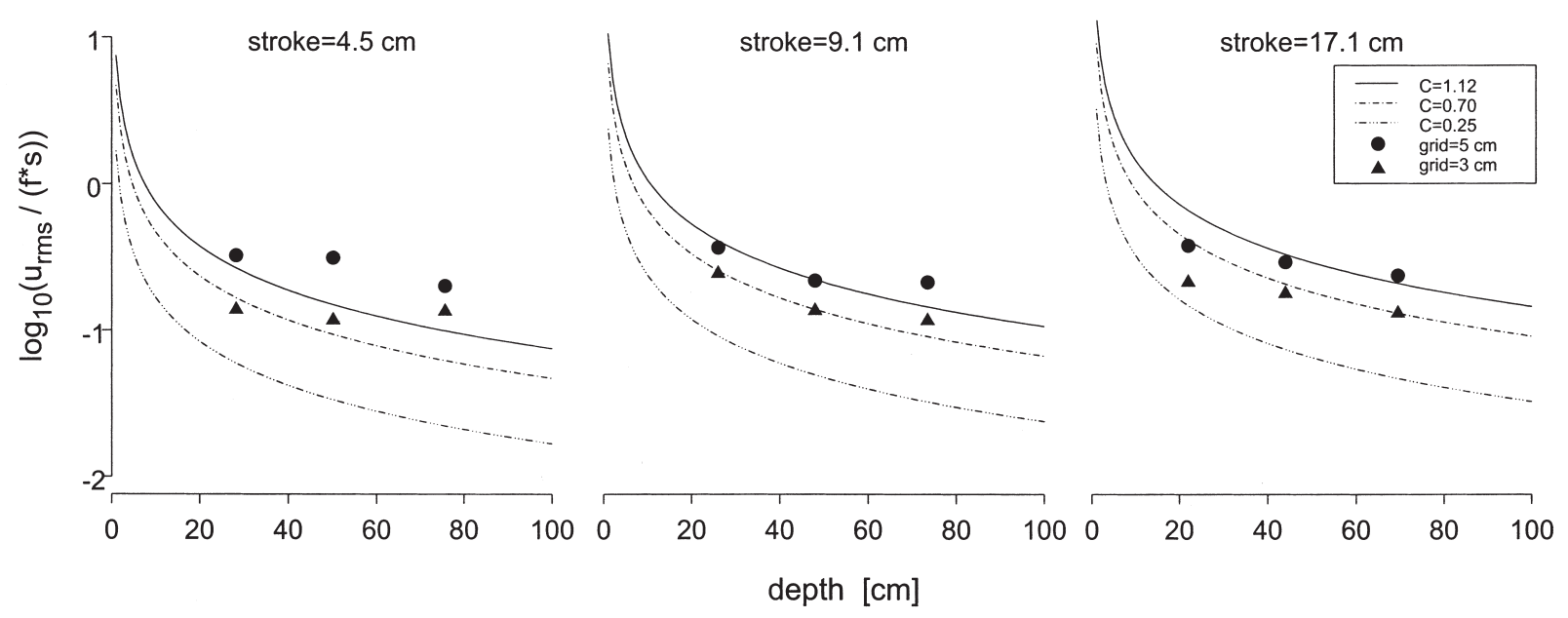

FIG. 6. - Non-dimensional root-mean-square turbulent velocity data $\left(\mathrm{u}_{\mathrm{rms}} /(\mathrm{f} * \mathrm{~s})\right.$, where $\mathrm{f}$ is the grid oscillation frequency and $\mathrm{s}$ the stroke) compared to the decay formula with distance from grid given by Hopfinger and Toly (1976) (Eq. 11). The panels show the case for each of the three stroke regimes. The circles and triangles are the average values of the data with $5 \mathrm{~cm}$ and $3 \mathrm{~cm}$ grid bar width, respectively. The lines are drawn using the formulas original value of $\mathrm{C}=0.25$ (dotted lines), the average value from the data with the $5 \mathrm{~cm}$ bar width (solid line, $\mathrm{C}=$ 1.12) and the average value from the data with the $3 \mathrm{~cm}$ bar width (dot-bar-dot line, $C=0.70$ ). The average value of $C$ from the data is equal for all three strokes.

out the tank (Figs. 5b and 5d). A reduction of the grid stroke from $17.1 \mathrm{~cm}$ to $4.5 \mathrm{~cm}$ resulted in a drop in the energy level of two orders of magnitude (Figs. $5 \mathrm{~b}$ and $5 \mathrm{e}$ ). A similar change of energy level (of almost 2 orders of magnitude ) occurred when the frequency was reduced by a factor of 3.5 , from 0.12 (period $8.5 \mathrm{~s})$ to 0.033 (period $30 \mathrm{~s}$ ) (Figs. 5a-c). Energy dissipation rates in position $1 \mathrm{C}, 2 \mathrm{~B}$ and $3 \mathrm{~A}$ for the two grids are shown in Table 1.

Hopfinger and Toly (1976) gave the non-dimensional formula:

$$
\frac{u_{r m s}}{f S}=\frac{C \sqrt{S M}}{z}
$$

for the decay of the turbulent intensity with increasing distance from the oscillating grid. Here $f$ is the oscillation frequency, $\mathrm{S}$ is the stroke and $\mathrm{M}$ the mesh size of the grid and $\mathrm{z}$ the distance from what they called the virtual origin, which is close to the midpoint of the grid oscillation. $\mathrm{C}$ is a constant specific to the type of grid used and estimated by Hopfinger and Toly (1976) to 0.25 for square grids. The constant $\mathrm{C}$ was calculated from Equation 12 for each grid and had a mean value of 0.70 and 1.12 with a standard deviation of 0.38 and 0.47 for the 3 and 5 $\mathrm{cm}$ grid, respectively. Data compared with Equation 12 for the midpoint of the grid oscillation as origin, using the calculated values of $\mathrm{C}$ together with the value given by Hopfinger and Toly (1976) for the three used strokes 4.5, 9.1 and $17.1 \mathrm{~cm}$ respectively are shown in Figure 6. Overlayed is the average value of the non-dimensional turbulent velocity, $\hat{\mathrm{u}}=\mathrm{u}_{\mathrm{rms}} / \mathrm{fS}$, calculated from the data shown as triangles ( $3 \mathrm{~cm}$ grid) and circles ( $5 \mathrm{~cm}$ grid). Because the base of the grid had at a constant depth the z-values of the measuring positions depended on the stroke. The calculated value of the non-dimensional turbulent velocity ( $\hat{u})$ did not follow the slope of the curve completely but deviated with a smaller slope.

Visual and video observations of the tank reveal a mean circulation in the tank with an upward direction in the centre of the tank and a downward direction at the walls and going below the grid. Figure 7 shows a sketch this circulation pattern. The narrow current was strongest along the centre and wall leaving a larger undisturbed volume in-

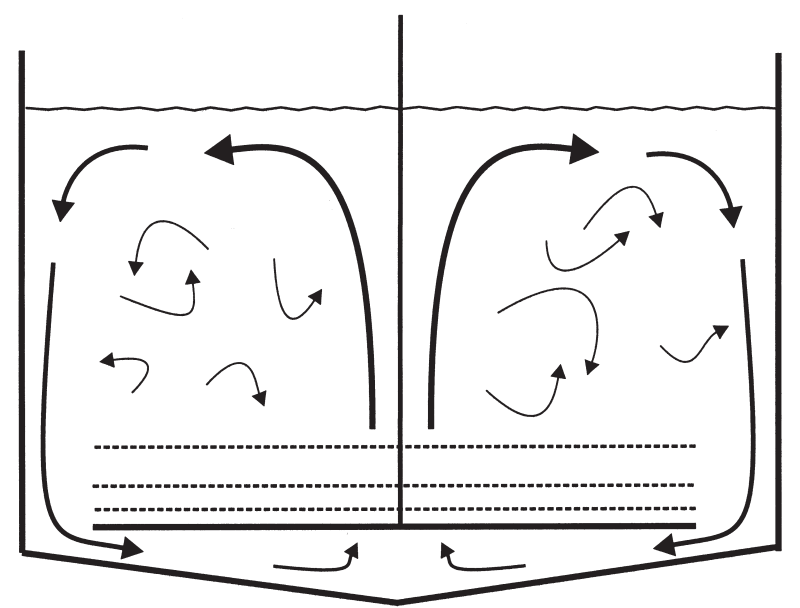

FIG. 7. - Sketch of the circulation pattern in the tank interpreted from the particulate saw dust movement and from the UCM measurements. 
between. The velocities of the current increased with the energy dissipation rate, which is coupled to the stroke, frequency and bar width. In addition, a quasi-horizontal circulation pattern was also observed, which changed its spatial intensity over time with a period of about 1 minute. We believe this effect is due to the size of the tank in combination with a slight flexibility in the rod driving the grid up and down.

\section{DISCUSSION}

\section{The size of the present set-up}

The present experimental set-up enables us to simulate more realistically the physical and biological environmental conditions of larval fish feeding. In nature the early stages of fish larvae are found at typical maximum concentrations of 1-10 ind. $\mathrm{m}^{-3}$, while their prey, for example the copepod nauplii, are found at typical maximum concentrations of 1,000-10,000 ind. $\mathrm{m}^{-3}$ (e.g. Sundby, 1997). This implies that the natural distance between individual larval fish is of the order of one metre while distance between prey particles is 1 to $10 \mathrm{~cm}$. In most aquarium experiments concentration of both fish larvae and their prey are exaggerated by several orders of magnitude compared to nature. If not, there would hardly have been any organisms in the experimental volume at all. Such conditions can, however, create a number of artefacts connected to physical and biological processes. Cannibalism of larval fish is a problem in many rearing experiments, probably a result of the high concentration of the fish larvae and to higher than natural ratios between fish larvae and their prey. In nature an early stage fish larva will encounter about 1000 prey items before it encounters another fish larva. It indicates that cannibalism at this early stage must be very small compared to the highly concentrated laboratory conditions. Consequently, it might be expected that the behaviour of the larvae also would be very different. In small aquaria the maximum length scale for turbulent energy is necessarily limited to the size of the aquarium. It implies that the fluid dynamics of plankton interactions on larger, more natural length scales (metres, or even decimetres), will not be simulated, and the spatial scale of the turbulent energy cascade is not reproduced. The present study will enable us to make feeding experiments both with more natural plankton concentra- tions and under more natural turbulent conditions with respect to spatial scales.

The circular shape of the tank is more favourable for generating homogeneous turbulence than a rectangular shape, since the decay of the turbulence towards the walls is expected to be more homogeneous than in a rectangular tank where the corners will have different conditions for turbulent energy dissipation. Also, a circular tank will eliminate the possibility of larval congregation in the corners.

\section{The spatially structure of the turbulence}

The energy dissipation, and hence the kinetic turbulent energy, is high near the grid, but it decreases rapidly with the distance from the grid. This is described by the formula, Equation 12, given by Hopfinger and Toly (1976), and later verified by several authors (Hannoun and List, 1988, Redondo, 1988, Fernando, 1991). The present data show reasonably good agreement with Equation 12 when using the grid specific constant (C) in Equation 12, calculated from our data (see Fig. 6).

According to Hopfinger and Toly (1976) the constant $\mathrm{C}$ has to be determined for each type of grid. In our experiment the average value of $\mathrm{C}$ was 1.12 for the $5 \mathrm{~cm}$ grid and 0.70 for the $3 \mathrm{~cm}$ grid. This is much higher than the value 0.25 given by Hopfinger and Toly signifying a higher turbulent energy with the same stroke and oscillation frequency than the grid used by Hopfinger and Toly (1976). This might be due to our particular bar width/mesh size ratio, bar height and stiffness of the grid.

Our data deviate from the theoretical curve having higher $\mathrm{u}_{\mathrm{rms}}$ values at larger distances and giving a more homogenous spatial distribution of the kinetic energy than Hopfinger and Toly (1976). We suggest that the mean transport of turbulence is more efficiently in the present tank experiment. The dome-shaped distribution of the turbulent energy dissipation rate within the tank do support the view that the turbulence is effectively transported downstream of the circulation pattern. Also the use of a relatively low mesh size/bar width ratio compared to other experiments might contribute to the effective propagation of the turbulent energy. The constant $\mathrm{C}$ found in our data should be less in a situation without advection effects.

Biological experiments often require homogenity. The effect of advection might therefore be considered a desirable result of the set-up. Advection changes the spatial structure of the turbulent energy 
from horizontal to domeshaped as seen in all five panels of Figure 5. It was not possible to make velocity measurements below the grid because of the narrow space between the grid and the floor of the tank. The formula of Hopfinger and Toly (1976) is symmetrical and should apply in this volume as well, but due to the closeness to the bottom one cannot rule out wall effects. The mean current passing through the grid will also modify the results giving the opposite advective effect to that above the grid.

\section{Instrumental limitations}

The UCM-40 current meter used in the experiment has spatial limitations with respect to measuring smaller turbulent scales. The resulting velocity is based on measuring the time of flight difference of two sound wave, initiated simultaneous, propagating towards each other from sensors $12 \mathrm{~cm}$ apart. On the other hand, the temporal resolution of the UCM-40 measurements are $2 \mathrm{~Hz}$ (sampling rate is $20 \mathrm{~Hz}$ and internally averaged to $2 \mathrm{~Hz}$ before output), and the frequency spectra are based on the temporal velocity fluctuations. According to Soulsby (1980) a travel time difference meter with acoustic path length $\mathrm{L}$ will resolve up to $50 \%$ of the turbulence with eddy diameter equal to L, and $70 \%$ of the turbulent eddies of sizes 1.5L. Using Taylor hypothesis to transform the frequency to wavenumber $(k=2 \pi f / U)$ for the spectra in
Figures $4 \mathrm{a}$ and $4 \mathrm{~b}$, and calculating the eddy size ( $\mathrm{L}=\pi / \mathrm{k}$ ) according to Gytre et al. (1996) we get $\mathrm{L}=$ 3.8 and $0.56 \mathrm{~cm}$, respectively, for the Nyquist frequency $(1 \mathrm{~Hz})$, the ratio $\mathrm{U} / \mathrm{u}_{\mathrm{rms}}$ being respectively 2.9 and 3.4. Following the argument of Soulsby there should be an increasing drop from the $\mathrm{f}^{-5 / 3}$ slope at spectral densities below the frequency corresponding to the path length of the instrument $(\mathrm{f}=\mathrm{U} / 2 \mathrm{~L})$. For the experiments displayed in Figures $4 \mathrm{a}$ and $4 \mathrm{~b}$ the frequency corresponding to $\mathrm{L}=12 \mathrm{~cm}$ is 0.32 and 0.05 $\mathrm{Hz}$, respectively. This drop is not evident in the figures, or in any of the other measurements. The temporal resolution may compensate for the lower spatial resolution giving a good resolution of the eddy scales well within the relevant scales of fish larvae $(\mathrm{cm}-\mathrm{dm}$ scales). Although $2 \mathrm{~Hz}$ is not a high sampling frequency in turbulence measurements it is sufficient to solve the processes on the scale of $\mathrm{cm}$ and larger in our tank.

The white noise, mainly a result of velocity resolution of the UCM, is shown as a function of energy dissipation rate in Figure 8. The corresponding mean and root-mean-squared turbulent velocities are located along the same vertical line. When the mean velocity is below approximately $1 \mathrm{~cm} / \mathrm{s}$ the white noise is practically constant. As the mean velocity field increases further the white noise increases in accordance with the measuring principle (see Gytre, 1976) and the accuracy of the instrument, which is $3 \%$ of reading $+/-0.5 \mathrm{~cm} / \mathrm{s}$

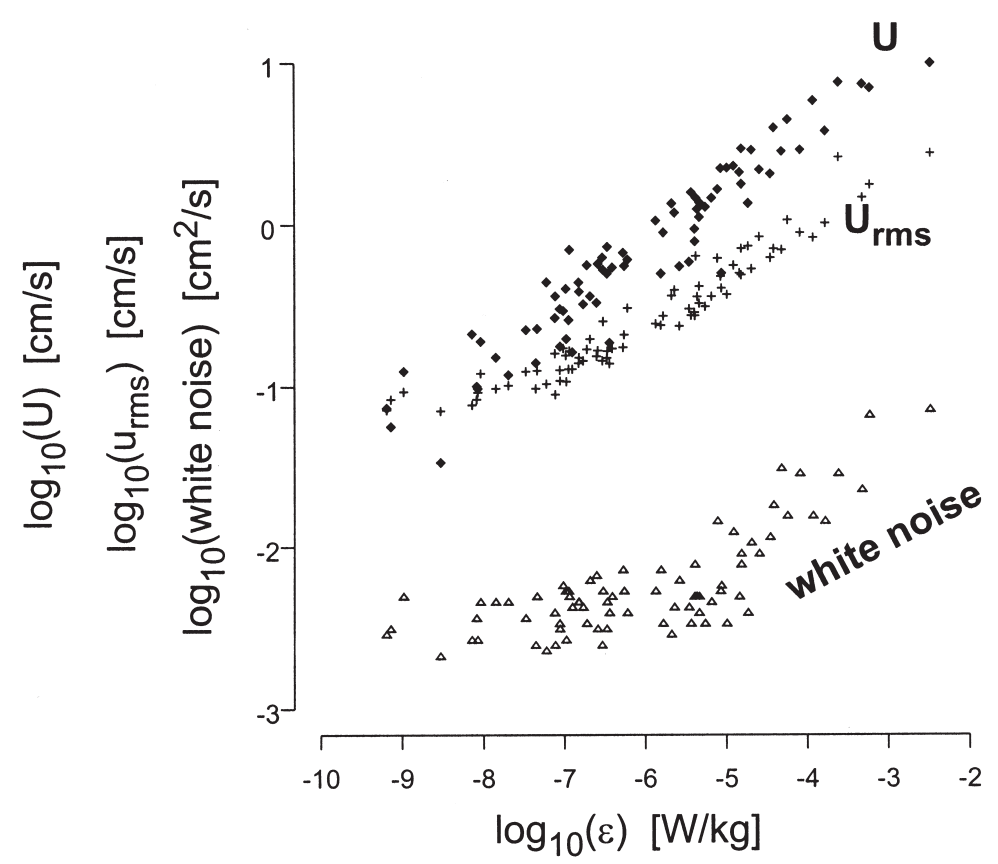

FIG. 8. - The white noise level (variance due to noise) and the mean and turbulent velocities as a function of energy dissipation rate for all positions shown in Fig. 1. Note that the white noise $\left(\mathrm{cm}^{2} / \mathrm{s}\right)$ and mean and turbulent velocities $(\mathrm{cm} / \mathrm{s})$ from the same measurement belongs to the same energy dissipation rate (located along the same vertical line). 

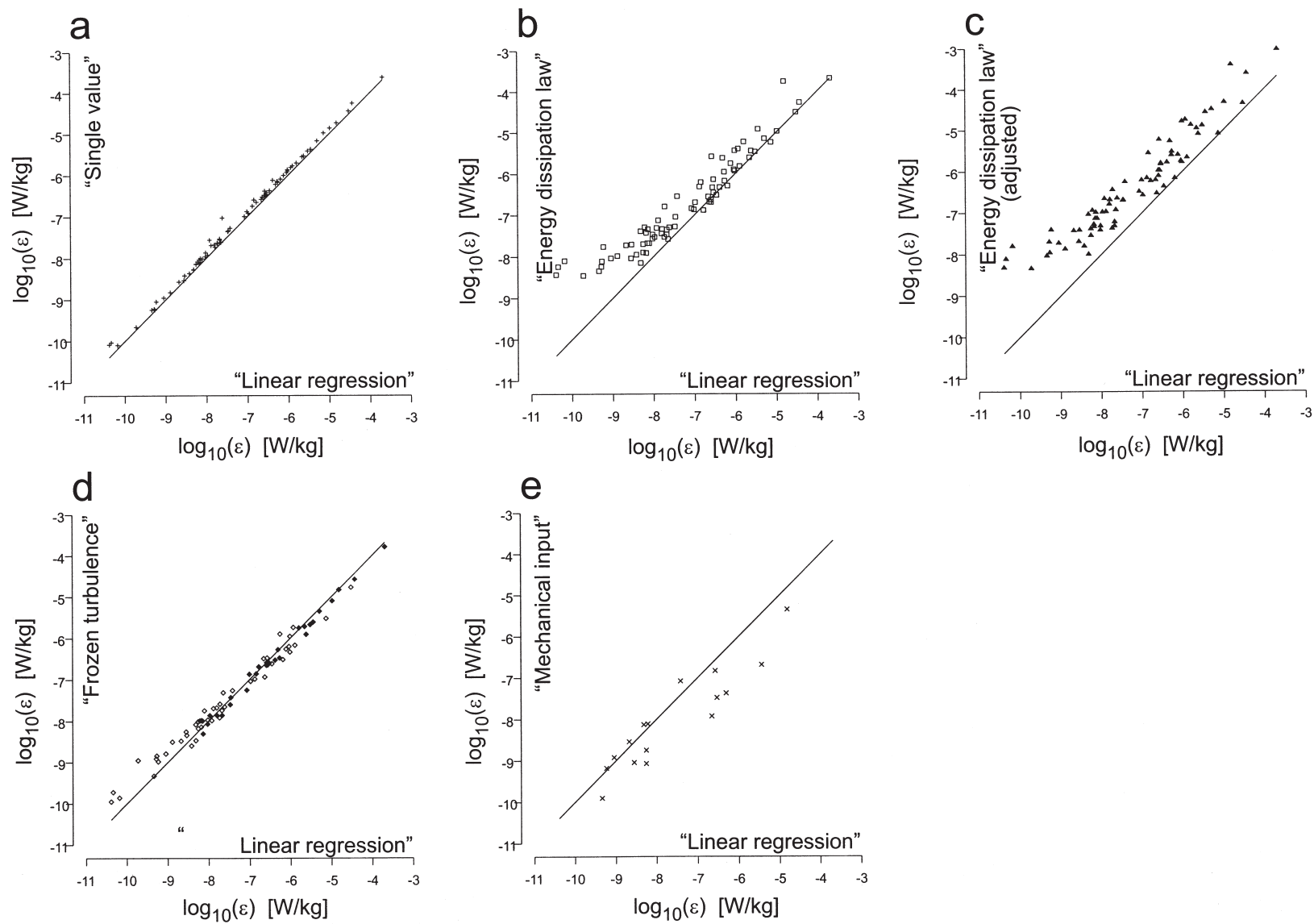

FIG. 9. - Comparison between the different methods (y-axis) for calculation of $\varepsilon$ vs. the linear regression method (x-axis). The solid line is a reference slope of 1 (linear regression vs. linear regression). a) The single value method (+). b) The energy dissipation law (open squares). c) The energy dissipation law adjusted for distance from grid (solid triangles). d) Taylor's 'frozen turbulence' hypothesis (open diamonds for $\mathrm{u}_{\mathrm{rms}} / \mathrm{U} \geq 0.5$ and solid diamonds for $\mathrm{u}_{\mathrm{rms}} / \mathrm{U}<0.5$ ). e) Mechanical input estimation (x). In e) only measurements from position 2B (see Fig. 1)

\section{Estimation of the energy dissipation rate}

In the study of physical-biological interactions, turbulence in general and the energy dissipation rate in particular are key processes (Sanford, 1997). There has been much theoretical and numerical work in this field (e.g. Gerritsen and Strickler, 1977; Rothschild and Osborn, 1988; Yamazaki et al., 1991). Most of these works were on Lagrangian considerations where length scales and wavenumber were the basis for the approaches. In tank experiments with larger sizes it is practical to use methods based on measurements at a single point rather than one based on spatial differences at a specific time such as particle tracking by video recording (e.g. Marrasé et al., 1990). This requires a frequency approach to the problem (see Eqs. 1 and 3). Until now it has been a problem to estimate $\varepsilon$ for conditions of zero mean current in the system. The linear regression method (Eqs. 5 and 6) overcomes this problem and also eliminates the need of a characteristic length scale.
In order to test the linear regression method a comparison with other methods has been carried out and the results are shown in Figure 9. Each compared method is listed below, with a short description.

The single value method - method ' $a$ '

It is possible to calculate $\varepsilon$ for each frequency $\left(\omega_{i}\right.$ in Eq. 1) in the inertial subrange, and then calculate the average value as follows, in terms of angular frequency:

$$
\begin{gathered}
\varepsilon_{i}=\left(\frac{S\left(\omega_{i}\right) \omega_{i}^{5 / 3}}{B u_{r m s}^{2 / 3}}\right)^{3 / 2} \\
\bar{\varepsilon}=\frac{1}{N} \sum_{i=1}^{N} \varepsilon_{i}
\end{gathered}
$$

or in terms of natural frequency:

$$
\varepsilon_{i}=2 \pi\left(\frac{S\left(f_{i}\right) f_{i}^{5 / 3}}{B u_{r m s}^{2 / 3}}\right)^{3 / 2}
$$


The energy dissipation law (after Frisch, 1995) method " $b$ "

According to Taylor (1935) $\varepsilon$ can be calculated as

$$
\varepsilon=\mathrm{D} \mathrm{u} \mathrm{urs}^{3} / l
$$

where D is a universal constant assumed to be of order one (Moum, 1996) and $l$ is a characteristic length scale representing the larger vortices. In gridgenerated turbulence it is common to use the mesh size or the integral scale as the characteristic length scale (Peters and Redondo, 1997). In our calculations we used the mesh size of $l=10 \mathrm{~cm}$ and D was set to $\mathrm{D}=1$. Sreenivasan (1984) examined all earlier experimental data using the integral length scale and found that $\mathrm{D}$ is dependant on the microscale Reynold number and approaches 1 from above when $R_{\lambda} \rightarrow \infty$. Direct numerical simulations by Jimenez et al. (1993) and Wang et al. (1996) found the same dependence on $\mathrm{R}_{\lambda}$ with values of $\mathrm{D}$ ranging from 1.81 to 0.43 .

The energy dissipation law - method " $c$ " (adjusted for distance from grid)

In order to account for the increase in $l$ with distance from grid, Thompson and Turner (1975) gave the empirical relationship

$$
l=\beta \mathrm{z}
$$

for the integral scale of turbulence, where $\mathrm{z}$ is the distance from the centre of the oscillating grid and $\beta$ a proportionality constant of $\beta=0.1$.

\section{Taylor's 'frozen turbulence' hypothesis - method " $d$ "}

If turbulence is advected past a point by a mean current (U) fast enough so the spatial structure of the turbulence does not change considerably during the measurement the velocity series $u$ can be transformed from a time domain $\mathrm{u}(\mathrm{t})$ to a spatial domain $\mathrm{u}(\mathrm{x} / \mathrm{U})$, where $\mathrm{x}$ is the travelled distance. This transform is called Taylor hypothesis of 'frozen turbulence' and is the most common way to calculate $\varepsilon$. This method is useful only when $\mathrm{u}^{\prime} / \mathrm{U}<<1$.

In spectral space a change from the angular frequency into a wavenumber $(\mathrm{k})$ takes place by the transform $\mathrm{k}=\omega / \mathrm{U}$. Substituting this into Equation 3 (ensuring conservation of energy in the spectrum) and solving for $\varepsilon$ gives, in term of angular frequency:

$$
\varepsilon=\left(\frac{S(\omega) \omega^{5 / 3}}{A U^{2 / 3}}\right)^{3 / 2}
$$

and in term of natural frequency:

$$
\varepsilon=2 \pi\left(\frac{S(f) f^{5 / 3}}{A U^{2 / 3}}\right)^{3 / 2}
$$

$\mathrm{S}(\omega)$ or $\mathrm{S}(\mathrm{f})$ can be found either by linear regression (as in Eq. 5 or Eq. 6, respectively) or by single values (as in method "a"). In our calculations we used Equation 19.

\section{Mechanical input estimation - method " $e$ "}

A rough estimate of the average $\varepsilon$ in the tank can be calculated from the mechanical motion of the grid. The total energy input (E) from the grid can be expressed as $E=\tau A s$, where $\tau$ is the stress applied by the grid over the distance s and area $\mathrm{A}$. The energy dissipation rate in the stationary and homogenous case can then be expressed as $\varepsilon=\mathrm{E} / \mathrm{mt}$, where $\mathrm{m}$ is the total mass in the tank and $t$ is the duration of the energy input to consider. The stress is given by $\tau=$ $C_{D} \rho v^{2}$, where $C_{D}=1.4^{*} 10^{-3}$ is the drag coefficient, $\rho$ the density of the fluid and $\mathrm{v}$ the grid velocity. The mass can be expressed as $\mathrm{m}=\rho \mathrm{V}$ where $\mathrm{V}$ is the volume of the tank. If $\mathrm{s}$ is the stroke of the grid and $\mathrm{t}=\mathrm{P} / 2$, where $\mathrm{P}$ is the grid oscillation period, the energy dissipation rate can be expressed as $\varepsilon=\left(C_{D}\right.$ $\left.\mathrm{v}^{2} \mathrm{As}\right) /(0.5 \mathrm{PV})$. The squared velocity, represented by the average cube velocity $\left(\left\langle v^{2}\right\rangle\right)$, over half a sinusoidal cycle is $\mathrm{v}^{2}=\left\langle\mathrm{v}^{2}\right\rangle=0.5 \pi^{2} \mathrm{~s}^{2} / \mathrm{P}^{2}$. This gives the dissipation as

$$
\varepsilon=C_{D} \pi^{2} \frac{A}{V}\left(\frac{s}{P}\right)^{3}
$$

Table 2 gives the mean average ratio between the different methods, with one standard deviations, and Table 3 the correlation's between the methods. A high correlation (r) indicates that the different methods are equal by a constant coefficient, which is the ratio given in Table 2. When the correlation is low, the value in Table 2 can not be used in this way.

The method of single value (method "a") shows good agreement with the linear regression method (Fig. 9a, $r=0.9986$ ) and a ratio difference of 0.77 . This is not surprising since they are just variants of each other. The relationship between the linear regression method and method "b" (Fig. 9b) shows a difference of about one half order of magnitude, and a correlation of 0.81 . However, when one corrects for the increase in $l$ (method "c") the correla- 
TABLE 2. - The average value of the ratio between the energy dissipation calculated in pairs (i,j) for the different methods $\overline{\varepsilon_{i} / \varepsilon_{j}} \pm$ one standard deviation. Method "lin" is the linear regression method,"a" is the single value method, "b" is the energy dissipation law, "c" is the energy dissipation law adjusted for distance from grid , "d" is Taylor's 'frozen turbulence' hypothesis and "e" is the mechanical input estimation (only position $2 \mathrm{~B}$ ).

\begin{tabular}{|c|c|c|c|c|c|c|}
\hline $\mathrm{i} \backslash \mathrm{j}$ & "lin" & "a" & "b" & "c" & "d" & "e" \\
\hline $\begin{array}{l}\text { "lin" } \\
\text { "a" } \\
\text { "b" } \\
\text { "c" " } \\
\text { "d" } \\
\text { "e" }\end{array}$ & 1 & $\begin{array}{c}0.77 \pm 0.11 \\
1\end{array}$ & $\begin{array}{c}0.48 \pm 0.38 \\
0.64 \pm 0.48 \\
1\end{array}$ & $\begin{array}{c}0.21 \pm 0.20 \\
0.28 \pm 0.27 \\
0.46 \pm 0.20 \\
1\end{array}$ & $\begin{aligned} 1.05 & \pm 0.49 \\
1.42 & \pm 0.75 \\
4.8 & \pm 8.0 \\
10 & \pm 15 \\
1 & \end{aligned}$ & $\begin{array}{c}5.2 \pm 6.0 \\
6.4 \pm 7.2 \\
22 \pm 18 \\
49 \pm 41 \\
6.0 \pm 6.9 \\
1\end{array}$ \\
\hline
\end{tabular}

TABLE 3. - Correlation between method i and j. The indexes refer to the same methods as in Table 2.

\begin{tabular}{|c|c|c|c|c|c|c|}
\hline $\mathrm{i} \backslash \mathrm{j}$ & "lin" & "a" & "b" & "c" & "d" & "e" \\
\hline $\begin{array}{l}\text { "lin" } \\
\text { "a" } \\
\text { "b" } \\
\text { "c" } \\
\text { "d" } \\
\text { "e" }\end{array}$ & 1 & $\begin{array}{l}1.00 \\
1\end{array}$ & $\begin{array}{l}0.81 \\
0.82 \\
1\end{array}$ & $\begin{array}{l}0.94 \\
0.94 \\
0.95 \\
1\end{array}$ & $\begin{array}{l}1.00 \\
1.00 \\
0.82 \\
0.95 \\
1\end{array}$ & $\begin{array}{l}0.98 \\
0.98 \\
1.00 \\
1.00 \\
0.99 \\
1\end{array}$ \\
\hline
\end{tabular}

tion increases to 0.94 , but the difference ratio decreases to a factor 0.21 (see also Fig. 9c). Explicit calculations of the $l$ are not possible with a single point meter when there is no mean flow. This requires either measurements in two close positions at the same time or the presence of a mean flow. Method "d" shows good agreement with the linear regression method, (ratio $=1.05, r=1.00)$. This is surprising since the criteria of the method $\left(\mathrm{u}^{\prime} / \mathrm{U}<<\right.$ 1) is not met. In our calculations we used the total (3D) mean velocity (shown in Fig. 8). The ratio of turbulent and total mean velocity ranged from 0.14 to 2.1 , with $70 \%$ of the ratios less than 0.5 and $25 \%$ less than 0.25 (only $3 \%$ had a ratio higher than 1 ). For the mean of the velocity component, the ratio ranged from 0.18 to 6.3 , with $37 \%$ of ratios less than 0.5 (se Fig. 9) and 6\% less than 0.25, while $19 \%$ had a ratio larger than 1 . Consequently, it seems that Taylor's "frozen turbulence" hypothesis is valid even for ratios around 1. Method " $e$ " is a rough estimate of the mean dissipation rate in the tank, even so it shows reasonable agreement with the other methods. Our tank had a volume of $1.6 \mathrm{~m}^{3}$ and an area covered by the grid bars of 0.404 and $0.564 \mathrm{~m}^{2}$ for the 3 and $5 \mathrm{~cm}$ grid, respectively. Taking $\varepsilon$ in the middle of the tank (position 2B) as a typical average value for the majority of the volume in the tank (away from the stroke area) and comparing this with the linear regression method in the same position gives a ratio of $5.2(r=0.98)$. Method "e" can be a useful tool when designing the experiment, coupling desired energy dissipation rate to grid, stroke and period in a given tank volume.

The method of linear regression is an equally reliable method for estimating the energy dissipation rate as the others. The differences in results from the various method also show that care must be made whenever results from different methods of calculation are compared, with differences of one order of magnitude. Correlations between the methods are encouraging, because they show that the differences mainly have to do with setting of constants and appropriate length scales.

The constant B used in Equation 1 is not experimentally determined but assumed to be of order one (Tennekes and Lumley, 1974). In our calculations B is set equal to 1 , for convenience, but because $\varepsilon$ is proportional to $\mathrm{B}^{-3 / 2}$ (see Eq. 6) a different value would have a greater impact on the calculations. For instance a change in B to 0.1 or 10 will affect $\varepsilon$ by a factor 30 or 0.03 , respectively. Though the value of B has not been established Sandford (1997) uses the value of $\mathrm{B}=0.65$ (His constant $\mathrm{C}=1.9$ is equal to $\mathrm{B}^{-3 / 2}$ ). However, his value is taken from a Taylor hypothesis transformation given in Terray et al. (1996) and yield the root-mean-square velocity of surface waves $\left(\mathrm{U}_{\mathrm{w}}\right)$. Terray et al. (1996) refered to the results of Lumley and Terray (1983) and gave the value $\mathrm{C} \approx 2.7$ when considering $\mathrm{U}_{\mathrm{w}}$, which relates to the mean velocity as $U=U_{w} * \sqrt{ } 2$. This 
gives $B=C^{-2 / 3}=0.52$, but relates to wave velocity and not turbulent velocity. Lumley and Terray (1983) also noted that the transverse and streamwise spectra tend to be equal at high frequencies. Kitaigorodskii et al. (1983) used the same data as Lumley and Terray (1983). From Table 2 in Kitaigorodskii et al. (1983) we derive the turbulent velocity $\mathrm{u} \approx$ $1 / 2 * \mathrm{U}_{\mathrm{w}}$ in their experiment. In that case the constant in Terray et al. (1996) should be modified by a factor $1 /(2 * \sqrt{2})$ before used on turbulent velocities. This gives $\mathrm{B}=1.03$. The exact value of $\mathrm{B}$ will not change the comparisons between estimates based on the same B, though, since it is a universal constant. A future determination of $\mathrm{B}$ is desired. Our estimates of the energy dissipation rate can then easily be corrected.

The estimation of the constant $b$ in the linear regression should be carried out with the greatest care because of the power dependence on $\varepsilon\left(\varepsilon \propto\left(10^{b}\right)^{3 / 2}\right.$. If $\mathrm{b}$ is set $10 \%$ higher than the true value, $\varepsilon$ will be overestimated by $40 \%$. The corrected $u_{r m s}$ is not as sensitive to error estimations because of the linear relationship to $\varepsilon$, but failure to account for significant artificial peaks or high levels of white noise will seriously affect the calculations of $\varepsilon$.

The resolution limitations of the current meter prevented us from estimating the energy dissipation rates below approximately $5^{*} 10^{-11} \mathrm{~W} / \mathrm{kg}$.

\section{Stroke, period, grid, mesh size and the inverse cascade}

The inverse cascade seen in Figs. $4 \mathrm{a}$ and $4 \mathrm{c}$ is a typical phenomenon of 2-dimensional turbulence, but not documented for the 3-dimensional case. It seems that the inverse cascade works up to a level where the largest vortices are limited by the size of the tank. This seems to be valid independently of the input frequency, stroke or bar-width of the grid. The characteristic length scale $l$, is smaller than the largest eddies in the system. Since the tank has an upper limit for the eddy size the characteristic length scale has to be smaller than $1 \mathrm{~m}$. It is common to use the mesh size as the characteristic length scale. Since there is a constant difference between the size of the tank and the mesh size in a specific set-up one cannot tell whether the appropriate length scale should be based on the tank or the mesh size (or stroke). It seems likely that the size of the tank is the relative control mechanism for the largest eddies in the tank and thereby the size of $l$. If this is correct it becomes even more important to scale a system large enough to create a natural cascade over as wide inertial subrange as possible.

It is interesting to notice the large effect of bar size of the grid on the turbulence intensity. An increase in size from 3 to $5 \mathrm{~cm}$ increased the energy level one order of magnitude (Table 1). However, it appears that the variations in the grid stroke length from 4.1 to $17 \mathrm{~cm}$ are even more effective in generating variations in the turbulence intensity (see Fig. 5).

\section{Levels of turbulence generated compared to nature}

As pointed out by Peters and Redondo (1997) most of the laboratory experiments on the effects of turbulence on plankton have been carried out in regimes with much higher turbulent energy than normally found in nature. MacKenzie and Leggett (1993) estimated the effect of wind on the turbulent dissipation rate in the mixed layer and found that most of the turbulent level were found between $10^{-}$ 10 and $10^{-5} \mathrm{~W} / \mathrm{kg}$. Yamazaki and Osborn (1988) gave the interval $10^{-10}-10^{-2} \mathrm{~W} / \mathrm{kg}$ for the possible dissipation rates for the entire ocean including coastal waters and estuaries. The latter value is an extreme situation of strong tidal current, and such high values should be considered as rare events. With the ability to produce energy dissipation rates from $4^{*} 10^{-11}$ to $2 * 10^{-4} \mathrm{~W} / \mathrm{kg}$, our experimental setup should prove valuable for experiments on plankton in their natural range of turbulent exposure.

Gytre et al. (1996) described a field experiment in Lofoten, Northern Norway, in April 1995 and 1996. A underwater tower was used to mount a UCM $6 \mathrm{~m}$ above the bottom at a depth of $24 \mathrm{~m}$. The main sources of turbulence at this location were long swells and wind stress together with tidal currents. The natural cascade found in the field is also found in the tank and the turbulent levels found for this natural case are well within the levels created in the tank. The tank set-up therefore creates the same turbulent conditions found in the natural habitat of cod larvae.

\section{CONCLUDING REMARKS ON THE ADVANTAGES FOR USE IN PLANKTON- TURBULENCE STUDIES}

Most experiments with plankton and turbulence have been performed in smaller aquaria. However, in the last decade the number of experiments in 
larger systems involving turbulence has increased, recognising the need for natural plankton densities together with relevant turbulent scales. Howarth et al. (1993) studied N-fixation by cyanobacteria in 3 $\mathrm{m}^{3}$ tanks using a vertically oscillating grid. Petersen et al. (1998) investigated the effect of mixing in shallow planktonic ecosystems generating turbulence with rotating impellers in $1 \mathrm{~m}^{3}$ tanks. Svensen et al. (in press) used $30 \mathrm{~m}^{3}$ seabased enclosures in their investigation of effect of nutrients and turbulence on the planktonic foodweb and sedimentation. Turbulence was generated by vertically oscillating grids in the upper of a two layer density system. Other experiments can be found in the comprehensive review by Sanford (1997). However, experiments with fish larvae suffer from high concentrations of both larvae and prey. There is a lack of experiments on larvae under conditions where turbulence is believed to have the greatest impact: low densities of prey and predator. This is of great importance since the natural influence of turbulence on predator-prey interactions is limited to the spatial scale of separation distance between the planktonic organisms. Though, no experiment has been carried out in our system, it is our hope that such experiments will be done by future investigators.

Our data analyses indicate that the experimental set-up successfully simulated natural turbulence covering six orders of magnitude of energy dissipation rates $\left(4 * 10^{-11}-2 * 10^{-4} \mathrm{~W} / \mathrm{kg}\right)$ and almost three orders of spatial scales, from the Kolmogorov microscale $(0.3 \mathrm{~mm}-13 \mathrm{~mm})$ to the size of the tank $(\sim 1 \mathrm{~m})$. Consequently, we conclude that the tank is well suited for studies of plankton interactions, as the turbulence is generated on scales similar to the separation distance between the planktonic particles found in nature.

The short and relatively slow movement of the grid in addition to the relatively large volume of water should make it possible for the larvae to avoid extreme shears, and thereby minimise mechanical impact on larvae behaviour.

The linear regression method is shown to give a reasonable estimation of the energy dissipation rate in the tank for values expected to be found in ocean regimes. Since the method does not require a mean velocity field or any characteristic length scale it can be applied when data is collected in the field or laboratory using a high resolution single point current meter. The method is also useful for noisy time series.

\section{ACKNOWLEDGEMENTS}

This research is part of the project 'Recruitment Processes in Cod and Haddock' and was supported by the European Union, contract FAIR-CT95-0084. We want to thank Terje Van der Meeren for collaboration and assistance during the field work, and Signild Nerheim, Bjørn Ådlandsvik and Harald Svendsen for comments and discussions. We are also grateful for the thoroughly and constructive comments from the reviewers.

\section{REFERENCES}

Fernando, H.J.S. - 1991. Turbulent mixing in stratified fluids. Ann. Rev. Fluid Mech., 23: 455-493.

Frisch, U. - 1995. Turbulence: The legacy of A. N. Kolmogorov. University Press, Cambridge.

Gallego, A., M.R. Heath, E. McKenzie and L.H. Cargill. - 1996. Environmentally induced short-term variability in the growth rates of larval herring. Mar. Ecol. Prog. Ser., 137: 11-23

Gerritsen, J. and J.R. Strickler. - 1977. Encounter probabilities and community structure in zooplankton: A mathematical model. $J$. Fish. Res. Bd. Canada, 34: 73-82.

Gross, T.F., A.J. Williams and E.A. Terray. - 1994. Bottom boundary layer spectral dissipation estimates in the presence of wave motions. Cont. Shelf Res., 14: 1239-1256.

Gytre, T. - 1976. The use of a high sensitivity ultrasonic current meter in an oceanographic data acquisition system. The Radio and Electronic Engineer, 46 (12): 617-623.

Gytre, T., J.E.Ø. Nilsen, J.E. Stiansen and S. Sundby. - 1996. Resolving small scale turbulence with acoustic doppler and acoustic time difference current meters from an underwater tower. Ocean 96 proc., IEEE, pp. 442-450.

Hannoun, I.A. and E.J. List. - 1988. Turbulent mixing at a shearfree density interface, J. Fluid Mech., 189: 211-234.

Hopfinger, E. J. and J.-A. Toly. - 1976. Spatially decaying turbulence and its relation to mixing across density interfaces. $J$. Fluid Mech., 78: 155-175.

Howarth, R.W., T. Butler and K. Lunde. - 1993. Turbulence and planktonic nitrogen fixation: A mesocosm experiment. Limnol. Oceanogr., 38(8): 1696-1711.

Irigoien, X., R.P. Harris and R.N. Head. - 2000. Does turbulence play a role in feeding and reproduction of Calanus finmarchicus? J. Plankton Res., 22(2): 399-407.

Jimenez, J., A.A. Wray, P.G. Saffman and R.S. Rogallo. - 1993. The structure of intense vorticity in homogenous isotropic turbulence. J. Fluid Mech., 255: 65-90.

Kitaigorodskii, S.A., M.A. Donelan, J.L. Lumley and E.A. Terray. - 1983. Wave-turbulence interactions in the upper Ocean. Part II: Statistical characteristics of wave and turbulent components of the random velocity field in the marine surface layer. J. Phys. Oceanogr., 13: 1988-1999.

Kiørboe, T. - 1993. Turbulence, phytoplankton cell size, and the structure of pelagic food webs. Adv. Mar. Biol., 29: 1-72.

Kolmogorov, A.N. - 1941. The local structure of turbulence in incompressible viscous fluid for very large Reynolds number. Dokl. Akad. Nauk SSSR, 30: 9-13. (Reprinted in English in Proc. Roy. Soc. Lon. A, 434: 9-13, 1991.)

Kraus, E.B. and J.S. Turner. - 1967. A one-dimensional model of the seasonal thermocline. II. The general theory and its consequences. Tellus, 19: 98-105.

Lumley, J.L. and E.A. Terray. - 1983. Kinematics of turbulence convected by a random wave field. J. Phys. Oceanogr., 13: 2000-2007.

MacKenzie, B.R. and W.C. Leggett. - 1993. Wind-based models for estimating the dissipation rates of turbulent energy in aquatic environments: empirical comparisons. Mar. Ecol. Prog. Ser., 94: 207-216.

Marrasé, C., J.H. Costello, T. Granata and J.R. Strickler. - 1990. 
Grazing in a turbulent environment: Energy dissipation, encounter rates, and efficacy of feeding currents in Centropages hamatus. Proc. Natl. Acad. Sci. USA, 87: 1653-1657.

Moum, J.N. - 1996. Energy-containing scales of turbulence in the ocean. J. Geophys. Res., 101: 14095-14109.

Obukhov, A.M. - 1941a. On the distribution of energy in the spectrum of turbulent flow. Dokl. Akad. Nauk SSSR, 32 (1): 22-24.

Obukhov, A.M. - 1941b. Spectral energy distribution in a turbulent flow. Izv. Akad. Nauk SSSR Ser. Geogr. Geofiz., 5 (4-5): 453-466.

Osborn, T. and A. Scotti. - 1996. Effect of turbulence on predatorprey contact rates: where do we go from here? Mar. Ecol. Prog. Ser., 139: 302-304.

Peters, F. and J.M. Redondo. - 1997. Turbulence generation and measurement: application to studies on plankton. Sci. Mar., 61(Supl. 1): 205-228.

Petersen, J.E., L.P. Sandford and W.M. Kemp. - 1998. Coastal plankton responses to turbulent mixing in experimental ecosystems. Mar. Ecol. Prog. Ser., 171: 23-41.

Redondo, J.M. - 1988. Difusión turbulenta por rejilla oscilante. Revista de Geofísica, 44: 163-174.

Rothschild, B.J. and T.R. Osborn. - 1988. Small-scale turbulence and plankton contact rates. J. Plankton Res., 10 (3): 465-474.

Sanford, L.A. - 1997. Turbulent mixing in experimental ecosystem studies. Mar. Ecol. Prog. Ser., 161: 265-239.

Soulsby, R.L. - 1980. Selecting record length and digitalisation rate for near-bed turbulence measurements. J. Phys. Oceanogr., 10: 208-219.

Sreenivasan, K.R. - 1984. On the scaling of the turbulence energy dissipation rate. Phys. Fluids, 27 (5): 1048-1051.

Sreenivasan, K.R. - 1995. On the universality of the Kolmogorov constant. Phys. Fluids, 7 (11): 2778-2784

Sundby, S. - 1996. Turbulence-induced contact rates in plankton: the issue of scales. Mar. Ecol. Prog. Ser., 139: 305-307.

Sundby, S. - 1997. Turbulence and ichtyoplankton - influence on vertical distributions and encounter rates. Sci. Mar., 61(Suppl. 1): $159-176$

Sundby, S., B. Ellertsen and P. Fossum. - 1994. Encounter rates between first feeding cod larvae and their prey during moderate to strong winds. ICES Mar. Sci. Symp., 198: 393-405.

Sundby, S. and P. Fossum. - 1990. Feeding conditions of ArctoNorwegian cod larvae compared to the Rothschild-Osborn theory on small-scale turbulence and plankton contact rates. $J$. Plankton Res., 12 (6): 1153-1162.

Svensen, C., J.K. Egge and J.E. Stiansen. - in press. Can silicate and turbulence regulate the vertical flux of biogenic matter? A mesocosm study. Mar. Ecol. Prog. Ser.

Taylor, G.I. - 1935, Statistical theory of turbulence. Proc. Roy. Soc. Lon. A, 151, 421.

Tennekes, H. - 1975. Eulerian and Lagrangian time microscales in isotropic turbulence. J. Fluid Mech., 67: 561-567.

Tennekes, H. and J.L. Lumley. - 1974: A First Course in Turbulence, The MIT Press, 3. edition, Cambridge MA.

Terray, E.A., M.A. Donelan, Y.C. Agrawal, W.M. Drennan, K.K. Kahma, A.J. Williams III, P.A. Hwang and S.A. Kitaigorodskii. - 1996. Estimates of kinetic energy dissipation under breaking waves. J. Phys. Oceanogr., 26: 792-807.

Thompson, S.M. and J.S. Turner. - 1975. Mixing across an interface due to turbulence generated by an oscillating grid. J. Fluid Mech., 67: 349-368.

Turner, J.S. and E.B. Kraus. - 1967. A one-dimensional model of the seasonal thermocline. I. A laboratory experiment and its interpretations. Tellus, 19: 88-97.

Wang, L.P., S. Chen, J.G. Brasseur and J.C. Wyngaard. - 1996. Examination of hypotheses in the Kolmogorov refined turbulence theory through high-resolution simulations. J. Fluid Mech., 309:113-156.

Yamazaki, H. and T.R. Osborn. - 1988. Review of oceanic turbulence: implications for biodynamics. In: Rothschild, B.J. (ed.), Toward a theory on biological-physical interactions in the world ocean, pp. 215-234. Kluwer Academic Publishers, Dordrecht.

Yamazaki, H., T.R. Osborn and K. Squires. - 1991. Direct simulation of planktonic contact in turbulent flow. J. Plankton Res., 13 (3): 629-643.

Scient. ed.: C. Marrasé 